\title{
Pengaruh Pemberian Kuis Terhadap Peningkatan Motivasi Belajar Biologi Siswa di SMA Negeri 7 Kerinci
}

\author{
${ }^{1}$ Tomi Apra Santosa, ${ }^{2}$ Sisi Yulianti \\ ${ }^{1}$ Prodi Pendidikan Biologi, FMIPA, Universitas Negeri Padang. \\ ${ }^{2}$ Prodi Biologi, FMIPA, Universitas Andalas. \\ Email Korespondensi: santosatomiapra@gmail.com
}

Article Info
Article History
Received: 01 September
2020
Revised: $05 \quad$ September
2020
Published: 25 September
2020
Keywords
Learning
Quizzes
Learing Motivation

Informasi Artikel

Sejarah Artikel

Diterima: 01 September 2020

Direvisi: 05 September 2020

Dipublikasi: 25 Septembr 2020

Kata kunci

Pembelajaran

Kuis

Motivasi Belajar

\begin{abstract}
The study aims to find out how the increased motivation of learning students are quizzed and not given in biological learning. The research used is quantitative research with a pseudo-experimental method (quasi exsperimental research). The population of the study was SMA Negeri 7 Kerinci class $X$ consisting of 5 classes. Samples are XA and XB graders. Sampling techniques are Random sampling. The results of this study are the learning motivation of students given the quiz in learning Biology gained initial motivation (motivation) with a low category with a score of 58.882 and motivation to learn in the class of experimentation given treatment (treatment) by giving quizzes gained increased motivation learning with high category with a score of 91.25.
\end{abstract}

\begin{abstract}
Abstrak
Penelitian ini bertujuan untuk untuk mengetahui bagaimana peningkatan motivasi belajar siswa yang diberi kuis dan tidak diberi dalam pembelajaran biologi. Penelitian yang digunakan adalah penelitian kuantitatif dengan metode eksperimen semu (quasi exsperimen research). Populasi penelitian adalah siswa SMA Negeri 7 Kerinci kelas X yang terdiri dari 5 kelas. Sampel adalah siswa kelas XA dan XB. Teknik pengambilan sampel adalah Random sampling. Hasil penelitian ini adalah motivasi belajar siswa yang diberikan kuis dalam pembelajaran biologi diperoleh motivasi awal (premotivation) dengan kategori rendah dengan skor 58,882 dan motivasi belajar pada kelas eksperimen yang diberikan perlakuan (treatment) dengan pemberian kuis diperoleh peningkatan motivasi belajar dengan kategori tinggi dengan skor 91,25.
\end{abstract}

Sitasi: Santosa, Tomi Apra \& Yulianti, Sisi. (2020). Pengaruh Pemberian Kuis Terhadap Peningkatan Motivasi Belajar Biologi Siswa di SMA Negeri 7 Kerinci. Science Education and Application Journal. 2(2). $79-87$.

\section{PENDAHULUAN}

Pendidikan nasional harus memprioritas pada pendidikan sains agar semua siswa harus didorong untuk mengejar pendidikan semaksimal maungkin (Chi-Cheng et,al., 2011; Cormac G. Ryan,et,al., 2010). Kualitas pendidikan bisa ditingkatkan melalui perbaikan terhadap media belajar yang baik. Pemberian kuis merupakan salah satu metode pembelajaran yang dapat mendorong siswa untuk belajar dan dapat membuat siswa (Rasyid, 2014). Pemberian kuis sangat perlu diberikan kepada siswa agar motivasi siswa untuk belajar semakin baik serta dapat menghadapi kemajuan zaman. Perkembangan ilmu pengetahuan dan teknologi yang semakin pesat membawa berbagai permasalahan yang semakin rumit dan kompleks (Nurkanti et al., 2020). Pendidikan merupakan usaha sadar dan terencana untuk mewujudkan suasana belajar dan proses pembelajaran agar peserta didik secara aktif mengembangkan potensi dirinya (Mansur et al., 2018). Melalui pendidikan perilaku dan pola pikir peserta didik akan terbentuk. Indonesia sekarang ini tingkat pendidikannya masih tertinggal dibandingkan dengan negara lain. Hal ini dibuktikan dengan rendah minat hasil belajar siswa. Belajar adalah suatu proses 
perubahan dalam kepribadian manusia sebagai hasil dari pengalaman atau interaksi antara individu dan lingkungan (Litianingsih, 2020);. Dalam proses belajar mengajar keberhasilan siswa dipengauhi oleh strategi dan metode belajar (Tokan, 2019; Ummels, 2015; Arévalo, 2016). strategi dan metode belajar merupakan salah satu fatkto penyebab ketidakmampuan siswa mencapai hasil belajar yang diharapkan (Mursali, 2015). Selain itu kegiatan belajar siswa dapat berhasil apabila sesuai dengan tujuan yang belajar, yaitu dipengaruhi mengoptimalkan intelektual peserta didik sistem pengajaran, belajarnya serta efisien efektifitas proses pembelajaran, disamping itu sarana yang lengkap dan prasarana yang memadahi, juga sangat berpengaruh terhadap kelancaran pembelajaran (Nursalam, 2019). Pembelajaran adalah suatu usaha untuk membuat peserta didik belajar dan suatu kegiatan untuk membelajarkan serta cara bagi siswa untuk mencapai hasil yang diinginkan ((Sung et al., 2020; Rahman et al., 2020). Mengingat penting pembelajaran guru diharapkan dapat membangkitkan motivasi belajar siswa agar siswa dapat mendapatkan hasil yang diinginkan (Meishanti, 2019). Guru telah diakui sebagai agen kunci untuk mencapai masyarakat yang lebih berkelanjutan, menyediakan siswa dengan pengetahuan, kompetensi dan nilai-nilai untuk memungkinkan mereka untuk bertindak dalam cara-cara yang bertanggung jawab keberlanjutan (Kinh et al., 2016; Franke, 2011; Linda Fuselier, Azhar Bougary, 2018). Guru juga diharpakan bisa mengembangkan potensi siswa dalam pembelajaran sains,misalnya biologi. Biologi adalah ilmu pengetahun yang sangat signifikan dalam kehidupan siswa (Biology Education Research Group, 2014)

Biologi merupakan bagian dari IPA yang sangat besar pengaruhnya untuk penguasaan ilmu pengetahuan dan teknologi IPA juga berperan penting dalam upaya menyiapkan sumber daya manusia yang berkualitas (Septy Yustyan, Nur Widodo, 2015). Untuk mencapai itu semua guru harus menanamkan motivasi belajar siswa. Motivasi merupakan dorongan yang terdapat dalam diri seseorang untuk berusaha mengadakan perubahan tingkah laku yang lebih baik untuk memenuhi kebutuhannya (Uno, 2008). Motivasi sangat mempengaruhi pembelajaran siswa dalam mencapai hasil terbaik (Eka Putri Azrai \& Dian Evriyani, 2016). Dengan itu peserta didik atau siswa dituntut untuk mendapatkan hasil yang maksimal dalam belajar. Dengan demikian, alternatif untuk motivasi siswa untuk belajar yaitu dengan pemberian kuis. Pemeberian sangat dapat meningkatkan kualitas hasil pembelajaran nantinya akan berpngaruh langsung pada hasil belajar siswa (Trisna et al., 2017).

Dari penelitian sebelumnya yang dilakukan oleh Anggraini (2014) dan Trisna,dkk (2017) menunjukan Bernadeta Ayu Setyanta dan Enni Murwaningtya pada siswa kelas VIII SMP bahwa pemberian kuis kepada siswa sangat berpengaruh terhadap motivasi dan hasil belajar siswa. Hasil observasi di SMA N 7 Kerinci dengan menyebarkan angket motivasi ditemukan $50 \%$ siswa memiliki tingkat motivasi rendah. Guru harus memperhatikan motivasi, perhatian dan hasrat siswa (Tatang, 2012). Demikian guru dapat menerapkan evlauasi pembelajaran yang sesuai dengan agar memperoleh hasil belajar yang baik. Salah satu metode yang efektif adalah pemberian kuis. Pemberian kuis akan mendorong siswa menumbuh motif dan motivasi belajar (Raes et al., 2020). Pemberian kuis ini merupakan bentuk evaluasi hasil belajar siswa yang bertujuan untuk mengetahui penguasaan materi yang telah disampaikan oleh seorang guru. Penelitian ini bertujuan untuk mengetahui bagaimana pemberian kuis terhadap peningkatan motivasi belajar siswa di SMA Negeri 7 Kerinci.

\section{METODE}

Penelitian ini adalah penelitian kuantitatif dengan metode eksperimen semu (quasi exsperimen research ), indikator motivasi dalam penelitian yaitu 2 macam : 1) adanya hasrat dan keinginan untuk berhasil dan 2) adanya penghargaan dalam belajar. Penelitian eksperimen adalah penelitian yang melihat dan meneliti adanya akibat setelah subjek dikenai perlakuan pada variabel bebas (Sudrajat, 2005). Desain penelitian yang digunakan randomized control-group pretest -posttest design. Subjek penelitian adalah siswa SMA Negeri 7 Kerinci kelas X yang terdiri dari 5 kelas. Sampel penelitian siswa kelas XA sebagai kelas eksperimen yang terdiri 
dari 12 permpuan dan 16 orang laki dan siswa kelas XB yang terdiri dari 15 orang perempuan dan 13 orang laki-laki sebagai kelas kontrol dalam pengambilan sampel menggunakan teknik random sampling. Pengambilan subyek penelitian dengan cara mengambil tingkat hasil belajar yang berbeda. Tingkat motivasi belajarnya rendah dijadikan sebagai kelas eksperimen dan tingkat motivasi belajarnya tinggi dijadikan sebagai kelas kontrol. Teknik pengumpulan data menggunakan angket dan tes. Pengembangan instrumen angket menggunakan skala likert. Instrumen tes memperhatikan uji validitas, daya pembeda, indeks kesukaran, dan distraktor. Teknik analisis data menggunakan aplikasi SPSS berupa uji normalitas, uji homogenitas dan uji T.

\section{HASIL DAN PEMBAHASAN}

\section{Hasil Penelitian}

a. Motivasi belajar siswa yang diberi kuis pada pembelajaran biologi

Adapun hasil motivasi siswa dapat dilihat dari tabel dibawah ini.

\begin{tabular}{|c|c|c|c|}
\hline No & Nama & Pre-Motivation & Post-Motivation \\
\hline 1 & A1 & 68,75 & 82,50 \\
\hline 2 & $\mathrm{~A} 2$ & 59,38 & 73,13 \\
\hline 3 & A3 & 46,88 & 80,63 \\
\hline 4 & A4 & 66,88 & 77,50 \\
\hline 5 & A5 & 79,38 & 83,75 \\
\hline 6 & A6 & 68,13 & 80,00 \\
\hline 7 & A7 & 65,00 & 73,13 \\
\hline 8 & A8 & 51,25 & 91,25 \\
\hline 9 & A9 & 50,00 & 81,88 \\
\hline 10 & A10 & 65,63 & 75,00 \\
\hline 11 & A11 & 49,38 & 82,50 \\
\hline 12 & A12 & 41,88 & 81,88 \\
\hline 13 & A13 & 50,00 & 75,63 \\
\hline 14 & A14 & 53,75 & 81,88 \\
\hline 15 & A15 & 63,75 & 80,00 \\
\hline 16 & A16 & 75,00 & 81,88 \\
\hline 17 & A17 & 66,88 & 74,38 \\
\hline 18 & A18 & 51,88 & 80,63 \\
\hline 19 & A19 & 50,63 & 73,13 \\
\hline 20 & $\mathrm{~A} 20$ & 61,88 & 81,25 \\
\hline 21 & A21 & 51,88 & 82,50 \\
\hline
\end{tabular}




\begin{tabular}{|c|c|c|c|c|}
\hline No & Nama & Pre-Motivation & \multicolumn{2}{|c|}{ Post-Motivation } \\
\hline 22 & $\bar{A} 22$ & 59,38 & \multicolumn{2}{|l|}{76,88} \\
\hline 23 & A23 & 55,00 & \multicolumn{2}{|l|}{74,38} \\
\hline 24 & A24 & 51,88 & \multicolumn{2}{|l|}{90,00} \\
\hline 25 & A25 & 58,13 & \multicolumn{2}{|l|}{84,38} \\
\hline 26 & A26 & 48,75 & \multicolumn{2}{|l|}{83,75} \\
\hline 27 & A27 & 54,38 & \multicolumn{2}{|l|}{83,75} \\
\hline 28 & A28 & 71,88 & \multicolumn{2}{|l|}{84,38} \\
\hline \multicolumn{2}{|c|}{ TOTAL } & 1638 & \multicolumn{2}{|l|}{2252} \\
\hline \multicolumn{2}{|c|}{ Nilai Tertinggi } & \multicolumn{2}{|l|}{79,38} & 91,25 \\
\hline \multicolumn{2}{|c|}{ Nilai Terendah } & \multicolumn{2}{|l|}{41,88} & 73,13 \\
\hline \multicolumn{2}{|c|}{ Nilai Rata-rata } & 58,48 & & 80,42 \\
\hline
\end{tabular}

Berdasarkan tabel 1.1 diatas bahwa pada kelas eksperimen nilai motivasi awal (premotivation) tertinggi adalah 79,83 yang diraih oleh A5, sedangkan motivation awal (pre motivation) terendah adalah 41,88 yang diraih oleh A12. Selanjutnya dilihat dari rata-rata motivasi awal siswa kelas eksperimen diperoleh nilai motivasi awal (pre motivation) kelas eksperimen sebesar 58,82. Nilai rata-rata motivasi awal pada kelas eksperimen dikonsultasikan dengan indek kriteria skor pada tabel 1.1 maka nilai motivasi awal sebesar 58,82 dikategorikan rendah, berarti bahwa motivasi belajar biologi siswa kelas eksperimen (kelas XA) adalah kategori rendah. Motivasi akhir (post motivation) siswa kelas eksperimen setelah diberikan perlakuan dengan diajarkan dengan menggunakan kuis mengalami peningkatan, nilai tertinggi adalah 91,25 yang diperoleh oleh A8, dan nilai terendah adalah 73,13 diperoleh oleh A2,A7 dan A19. Jika dilihat rata-rata motivasi awal siswa kelas eksperimen diperoleh nilai motivasi akhir kelas eksperimen sebesar 80,42, jika dikonsultasikan dengan indek kriteria skor pada tabel 1.1 diperoleh motivasi akhir siswa kelas eksperimen sebesar 80,42 termasuk kategori tinggi, berarti bahwa motivasi belajar biologi siswa kelas eksperimen (kelas XA) adalah tinggi. Berdasarkan penjelasan diatas terjadi peningkatan motivasi belajar biologi siswa kelas eksperimen (XA) yang awalnya 58,82 dalam kategori rendah mengalami peningkatan setelah pemberian kuis sebesar 80,42 termasuk kategori tinggi.

\section{b. Motivasi belajar siswa yang tidak diberi kuis pada pembelajaran biologi}

Adapun untuk melihat hasil motivasi belajar biologi siswa yang tidak diberi kuis dapat dilihat pada tabel dibawah ini.

Tabel.2 Motivasi Awal dan Akhir Belajar Siswa pada Kelas Kontrol

\begin{tabular}{|c|c|c|c|}
\hline No & Nama & Pre-Motivation & Post-Motivation \\
\hline 1 & B1 & 75,63 & 75,63 \\
\hline 2 & B2 & 59,38 & 59,38 \\
\hline 3 & B3 & 48,13 & 49,38 \\
\hline 4 & B4 & 66,25 & 66,25 \\
\hline
\end{tabular}




\begin{tabular}{|c|c|c|c|c|c|}
\hline No & Nama & Pre-Motivatio & & Post-Motivat & \\
\hline 5 & B5 & $\overline{75,63}$ & & 77,50 & \\
\hline 6 & B6 & 69,38 & & 68,75 & \\
\hline 7 & B7 & 63,13 & & 65,00 & \\
\hline 8 & B8 & 50,00 & & 50,00 & \\
\hline 9 & B9 & 49,38 & & 49,38 & \\
\hline 10 & B10 & 67,50 & & 65,63 & \\
\hline 11 & B11 & 47,50 & & 48,75 & \\
\hline 12 & B12 & 43,13 & & 43,13 & \\
\hline 13 & B13 & 51,88 & & 50,00 & \\
\hline 14 & B14 & 53,75 & & 53,75 & \\
\hline 15 & B15 & 61,88 & & 63,75 & \\
\hline 16 & B16 & 74,38 & & 73,75 & \\
\hline 17 & B17 & 66,88 & & 65,63 & \\
\hline 18 & B18 & 48,13 & & 48,13 & \\
\hline 19 & B19 & 52,50 & & 51,88 & \\
\hline 20 & B20 & 63,13 & & 63,13 & \\
\hline 21 & B21 & 50,63 & & 50,63 & \\
\hline 22 & B22 & 57,50 & & 56,88 & \\
\hline 23 & B23 & 51,88 & & 51,88 & \\
\hline 24 & B24 & 49,38 & & 50,63 & \\
\hline 25 & B25 & 63,13 & & 60,63 & \\
\hline 26 & B26 & 50,63 & & 50,63 & \\
\hline 27 & B27 & 57,50 & & 57,50 & \\
\hline 28 & B28 & 78,75 & & 78,75 & \\
\hline & TOTAL & 1647 & & 1650 & \\
\hline \multicolumn{2}{|c|}{ NilaiTertinggi } & \multicolumn{2}{|r|}{78,75} & & 79,38 \\
\hline \multicolumn{2}{|c|}{ NilaiTerendah } & \multicolumn{2}{|r|}{43,13} & & 43,13 \\
\hline \multicolumn{2}{|c|}{ Nilai Rata-rata } & \multicolumn{2}{|r|}{58,82} & & 58,93 \\
\hline
\end{tabular}

Berdasarkan tabel 1.2 diatas diketahui bahwa pada kelas kontrol nilai motivasi awal (premotivation) tertinggi adalah 78,75 yang diraih oleh B28, sedangkan nilai motivasi awal (premotivation) terendah adalah 43,13 yang diraih oleh B12. Selanjutnya jika dilihat rata-rata motivasi awal siswa kelas kontrol di peroleh nilai motivasi awal (pre-motivation) kelas kontrol 
sebesar 58,82. Nilai rata-rata kelas pada motivasi awal (pre-motivation) selanjutnya dikonsultasikan dengan indeks kriteria skor pada tabel 4 maka nilai motivasi awal (premotivation sebesar 58,82 golongkan dalam kriteria kurang, yang berarti bahwa motivasi belajar biologi siswa kelas experimen (XB) adalah rendah. Selanjutnya motivasi akhir (posmotivation) siswa kelas kontrol, diketahui nilai tertinggi yang diraih siswa adalah sebesar 79,38 yang diraih oleh B1, dan nilai terendah adalah sebesar 43,13 yang diraih oleh B12. Selanjutnya jika dilihat rata-rata motivasi siswa kelas kontrol di peroleh nilai motivasi akhir (posmotivation) kelas kontrol sebesar 58,93. Nilai rata-rata kelas pada motivasi akhir (posmotivation) selanjutnya dikonsultasikan dengan indeks kriteria skor pada tabel 1.2 maka nilai motivasi akhir (pos-motivation)pada siswa kelas kontrol sebesar 58,93 termasuk dalam kriteria kurang, yang berarti bahwa motivasi belajar biologi siswa kelas experimen (XB) adalah kategori rendah. Berdasarkan penjelasan diatas terjadi peningkatan motivasi belajar biologi siswa kelas kontrol (X IPA 5) yang awalnya 58,82 meningkat menjadi 58,93. Walaupun terjadi peningkatan namun motivasi belajar biologi siswa pada kelas kontrol termasuk dalam kategori rendah.

\section{PEMBAHASAN}

Pada tabel 4 menunjukan nilai motivasi awal (pre-motivation sebesar 58,82 golongkan dalam kriteria kurang, yang berarti bahwa motivasi belajar biologi siswa kelas experimen (XA) adalah Kurang. Selanjutnya motivasi akhir (pos-motivation) siswa kelas eksperimen setelah dilakukan perlakuan (treatment) dengan diajar dengan menggunakan kuis mengalami peningkatan, nilai tertinggi yang diraih siswa adalah sebesar 91,25 yang diraih oleh A8, dan nilai terendah adalah sebesar 73,13 yang diraih oleh tiga orang siswa yaitu A2, A7, dan A19. Selanjutnya jika dilihat rata-rata motivasi awal siswa kelas eksperimen di peroleh nilai motivasi akhir (pos-motivation) kelas eksperimen sebesar 80,42 jika dikonsultasikan dengan indeks kriteria skor pada tabel 4 maka nilai motivasi akhir (pos-motivation) pada siswa kelas eksperimen sebesar 80,42 termasuk dalam kriteria baik, yang berarti bahwa motivasi belajar biologi siswa kelas experimen (XA) adalah Baik. Berdasarkan penjelasan diatas terjadi peningkatan motivasi belajar biologi siswa kelas eksperimen (XA) yang awalnya 58,82 golongkan dalam kriteria rendah mengalami peningkatan setelah diterapkannya kuis dalam pembelajaran biologi menjadi 80,42 termasuk dalam kriteria tinggi yang berarti bahwa kuis dalam pembelajaran biologi bisa meningkatkan motivasi siswa.

Pada kelas kontrol nilai motivasi awal (pre-motivation)tertinggi adalah 78,75 yang diraih oleH B28, sedangkan nilai motivasi awal (pre-motivation) terendah adalah 43,13 yang diraih oleh B12. Selanjutnya jika dilihat rata-rata motivasi awal siswa kelas kontrol di peroleh nilai motivasi awal (pre-motivation) kelas kontrol sebesar 58,82. Nilai rata-rata kelas pada motivasi awal (pre-motivation) selanjutnya dikonsultasikan dengan indeks kriteria skor pada tabel 1.1 maka nilai motivasi awal (pre-motivation sebesar 58,82 golongkan dalam kriteria kurang, yang berarti bahwa motivasi belajar biologi siswa kelas experimen (XB) adalah Kurang. Selanjutnya motivasi akhir (pos-motivation) siswa kelas kontrol, diketahui nilai tertinggi yang diraih siswa adalah sebesar 79,38 yang diraih oleh B1, dan nilai terendah adalah sebesar 43,13 yang diraih oleh B12. Selanjutnya jika dilihat rata-rata motivasi siswa kelas kontrol di peroleh nilai motivasi akhir (pos-motivation) kelas kontrol sebesar 58,93. Nilai rata-rata kelas pada motivasi akhir (pos-motivation) selanjutnya dikonsultasikan dengan indeks kriteria skor pada tabel 4 maka nilai motivasi akhir (pos-motivation) pada siswa kelas kontrol sebesar 58,93 termasuk dalam kriteria kurang, yang berarti bahwa motivasi belajar biologi siswa kelas experimen (X B) adalah rendah. Berdasarkan penjelasan diatas terjadi peningkatan motivasi belajar biologi siswa kelas kontrol (XB) yang awalnya 58,82 meningkat menjadi 58,93. Walaupun terjadi peningkatan namun motivasi belajar biologi siswa pada kelas kontrol termasuk dalam kriteria rendah. 
Perbandingan motivasi belajar dan kelas kontrol dilakukan untuk mengetahui perbedaan motivasi kedua kelas setelah dilakukan perlakuan (treatment) pada kelas eksperimen. Hasil perbandingannya adalah pada Kelas Eksperimen nilai motivasi awal (pre motivation) kelas experimen nilai tertinggi adalah 79,38 jika dibanding dengan kelas kontrol nilai tertinggi motivasi awal (pre motivation) sebesar 78,75. Selanjutnya nilai terendah pada kelas eksperimen sebesar 41,48 sedangkan pada kelas kontrol nilai terendah adalah 43,13, nilai rata-rata kelas eksperimen sebesar 58,48 jika dibandingkan dengan kelas kontrol yang nilai rata-rata nya sebesar 58,82 menunjukkan bahwa rata-rata motivasi belajar siswa kelas kontrol lebih tinggi dari pada kelas eksperimen pada motivasi awal (pre-motivation). Namun jika nilai rata-rata motivasi awal (pre-motivation) kelas eksperimen 58,48 dan kelas kontrol 58,82 di konsultasikan dengan indeks kriteria skor pada tabel 4.1 maka kedua kelas memiliki motivasi dengan kriteria kurang.Pada motivasi akhir (pos-motivation) belajar biologi siswa kelas eksperimen (XA) nilai tertinggi 91,25 sedangkan pada kelas kontrol ( XB) nilai tertinggi sebesar 79,38. Nilai terendah pada kelas experimen (pos-motivation) sebesar 73,13 sedangkan pada kelas kontrol sebesar 43,13. Nilai nilai rata-rata motivasi belajar biologi kelas eksperimen motivasi akhir (pos-motivation) sebesar 80,42 jika dibandingkan dengan kelas kontrol sebesar 58,93 menunjukkan bahwa rata-rata motivasi belajar siswa eksperimen lebih tinggi dari pada kelas kontrol begitu juga jika nilai rata-rata motivasi awal (pre-motivation) kelas kelas eksperimen 80,42 konsultasikan dengan indeks kriteria skor pada tabel 4 maka kelas eksperimen memiliki motivasi dengan kriteria baik sedangkan pada kelas kontrol 58,82 dengan kriteria rendah. Pemberian kuis sangat efektif untuk menigkatkan motivasi dan hasil belajar siswa (Side et al., 2017). Selain dapat meningkatkan motivasi belajar pemberian kuis sangat baik juga untuk meningkatkan hasil belajar siswa. Metode pemberian mampu meningkat 89,49 $\%$ hasil belajar siswa (Meishanti, 2019). Pemberian kuis merupakan salah satu cara untuk mencapai pembelajaran efektif bagi siswa dan guru (Cook et al., 2016).

Hasil perbandingan diatas menunjukkan bahwa siswa yang diberi kuis dalam pembelajaran biologi akan meningkatkan motivasi belajar mereka, hal tersebut perlu menjadi pertimbangan dan masukan bagi guru mata pelajaran biologi dalam membuat inovasi pembelajaran yang lebih menarik dan menyenangkan sehingga siswa tidak merasa bosan dan jenuh dalam kegiatan belajar mengajar dikelas. Selain itu proses pembelajaran biologi dengan menggunakan kuis terbukti dapat meningkatkan motivasi siswa yang awalnya kurang termotivasi dalam kegiatan belajar mengajarnya menjadi lebih termotivasi sebagaimana hasil penelitian ini. Hal ini telah dilakukan oleh Andini Agraini dalam penelitian pemberian kuis pada pembelajaran matematika. Hasil penelitiannya menunjukkan bahwa terjadi peningkatan hasil belajar yang terlihat dari skor rata-rata kemampuan awal siswa adalah 48,61 dengan skor ideal 100 yang berada pada kategori rendah, pada siklus I diperoleh skor rata-rata hasil belajar matematika siswa sebesar 70,61 dengan skor ideal 100 yang berada pada kategori tinggi, sedangkan pada siklus II menjadi 79,55 dengan skor ideal 100 yang berada pada kategori sangat tinggi (Angriani, 2014). Selain itu, Menurut I Komang Trisna pemberian kuis salah satu cara yang efektif untuk meningkat motivasi dan hasil belar siswa (Trisna et al., 2017). Hasil penelitiannya menunukan rata-rata nilai siswa dalam mengerjakan soal kuis di awal pembelajaran. Persentase ketuntasan pengerjaan soal kuis pada observasi awal sebesar $17,86 \%$ dengan rata-rata nilai 21,79 , meningkat menjadi $34,48 \%$ dengan rata-rata nilai 58,28 pada siklus I dan menjadi $72 \%$ dengan rata-rata nilai 80,60 pada siklus II. Hasil pengerjaan tes hasil belajar menunjukkan ketuntasan sebesar $80 \%$ dengan rata-rata nilai 79,59. Pemberian kuis pada siswa dapat meningkatkan $20 \%$ hasil belajar yang diharapkan guru (Blevins \& Besaw, 2011). Kuis merupakn metode alternatif bagi guru dalam pembelajaran untuk meningkatkan hasil dan motivasi belajar siswa (Turner, 2016; (Ziden et al., 2013). 


\section{KESIMPULAN}

Berdasarkan hasil penelitian diatas dapat disimpulkan bahwa pemberian kuis sangat efektif meningkatkan motivasi belajar siswa SMA Negeri 7 Kerinci. Dari data diatas menunjukan motivasi belajar siswa awalnya diperoleh skor 58,82 dan setelah pemberian kuis tingkat motivasi belajarnya naik menjadi 91,25.

\section{SARAN}

Penelitian ini diharapkan lebih dikembangkan agar kualitas pembelajaran dalam metode pemberian kuis kepada siswa dapat meningkatkan motivasi belajar dalam pembelajaran biologi di kelas.

\section{UCAPAN TERIMA KASIH}

Tidak lupa kami ucapakan terima kasih kepada Dosen pembimbing 1 dan 2 yang telah membimbing, melatih dan memotivasi kami sehingga kami dapat menyelesaikan artikel ini.

\section{DAFTAR PUSTAKA (12pt)}

Angriani, A. D. (2014). Meningkatkan hasil belajar matematika melalui pemberian kuis dengan umpan balik pada siswa kelas x6 sma negeri 2 sinjai. : : Jurnal Matematika Dan Pembelajaran, 2, 1-16.

Biology Education Research Group. (2014). How important is the assessment of practical work? An opinion piece on the new biology A-level from BERG. Journal of Biological Education, 48(4), 176-178. https://doi.org/10.1080/00219266.2014.956483

Blevins, A., \& Besaw, M. E. (2011). Reflecting on Quiz Placement in Online Tutorials : Creating a More Active Learning Experience Reflecting on Quiz Placement in Online Tutorials : Creating a More Active Learning Experience. Medical Reference Services Quarterly, October 2013, 37-41. https://doi.org/10.1080/02763869.2011.590427

Chi-Cheng Lin, Mark Bergland2, and K. K. (2011). Learner-centered methodology for designing and developing multimedia simulation for biology education. In Lecture Notes in Computer Science (including subseries Lecture Notes in Artificial Intelligence and Lecture Notes in Bioinformatics) (Vol. 6771, pp. 20-29). https://doi.org/10.1007/978-3642-21793-7_3

Cook, B. R., Babon, A., Cook, B. R., \& Babon, A. (2016). Active learning through online quizzes : better learning and less ( busy ) work. Journal of Geography in Higher Education, 34(3), 1-16. https://doi.org/10.1080/03098265.2016.1185772

Eka Putri Azrai, Dian Evriyani, A. R. P. (2016). HUBUNGAN TINGKAT KECEMASAN SISWA DALAM MENGHADAPI TES DENGAN TINGKAT MOTIVASI BELAJAR BIOLOGI PADA SISWA KELAS X MIA SMA NEGERI 21 JAKARTA. BIOSFER: JURNAL PENDIDIKAN BIOLOGI (BIOSFERJPB), 9(1), 47-54.

Kinh, T., Jane, K., Tracey, S., Gannon, J., Kieu, T. K., Singer, J., \& Gannon, T. J. (2016). Education for sustainable development in Vietnam: lessons learned from teacher education. International Journal of Sustainability in Higher Education, 17(6), 14676370. https://doi.org/10.1108/IJSHE-05-2015-0098

Litianingsih, D. (2020). PENGARUH MEDIA PEMBELAJARAN TERHADAP HASIL BELAJAR PESERTA DIDIK KELAS VII MATA PELAJARAN IPS DI MTS NEGERI 1 SITUBONDO SEMESTER GENAP TAHUN PELAJARAN 2018/2019. Jurnal Pendidikan Dan Kewirausahaan, 7(2), 25-34.

Mansur, S., Biologi, P., Nipa, U. N., \& Hidup, K. M. (2018). Pengaruh Pendekatan Jelajah Alam Sekitar ( JAS ) Terhadap Hasil Belajar Siswa pada Materi Klasifikasi Mahluk Hidup di SMPK Binawirawan Maumere. Bioeduscience, 2(20), 74-80. https://doi.org/10.29405/j.bes/74-80121314

Mursali, S. (2015). IMPLEMENTASI PERANGKAT PEMBELAJARAN BIOLOGI SMA 
BERBASIS METAKOGNITIF UNTUK MENINGKATKAN KEMAMPUAN KOGNITIF DAN MENGEMBANGKAN KARAKTER MANDIRI SISWA. JURNAL PENDIDIKAN BIOLOGI INDONESIA, 1(1997), 307-314.

Nurkanti, M., Kurniawan, I. S., Mayangsari, D. A., Suganda, H., \& Pasundan, U. (2020). Meningkatkan Hasil Belajar Siswa Menggunakan Teams Tournament ( TGT ) dan Permainan Hompimpa pada Materi Sel. Science Education and Application Journal (SEAJ, 2(1), 12-21.

Nursalam, J. H. (2019). PENERAPAN PEMBELAJARAN MODEL SOLUTION AND CRITIC GROUP UNTUK MENINGKATKAN AKTIVITAS DAN HASIL BELAJAR SISWA KOMPETENSI DASAR MENGINDENTIFIKASI BENTUK PASAR DALAM KEGIATAN EKONOMI MASYARAKAT PADA MATA PELAJARAN IPS KELAS VIII-B MTs AL-IMAN KLATAKAN SITUBON. Jurnal Pendidikan Dan Kewirausahaan, 6(2), 1-7.

Pea, O., \& Meishanti. (2019). PENGARUH PEMBERIAN KUIS TERHADAP HASIL BELAJAR SISWA. Eduscope, 05(01), 46-54.

Raes, A., Vanneste, P., Pieters, M., Windey, I., Van Den Noortgate, W., \& Depaepe, F. (2020). Learning and instruction in the hybrid virtual classroom: An investigation of students' engagement and the effect of quizzes. Computers and Education, 143(September 2019), 1-16. https://doi.org/10.1016/j.compedu.2019.103682

Rahman, R., Kondoy, E., \& Hasrin, A. (2020). Penggunaan Aplikasi Quizziz Sebagai Media Pemberian Kuis Dalam Meningkatkan Motivasi Belajar Mahasiswa. Jurnal Ilmu Sosial Dan Pendidikan, 4(3), 60-66.

Rasyid, M. (2014). Pengaruh Pemberian Kuis pada Pembelajaran Kooperatif Tipe Numbered Head Together ( NHT ) Terhadap Hasil Belajar Kimia Siswa Kelas XI IPA SMA Negeri 2 Pangkajene ( Studi Pada Materi Pokok Larutan Asam Basa) The Effect of Quiz on Numbered Head Together ( N (pp. 85-91).

Septy Yustyan, Nur Widodo, Y. P. (2015). PENINGKATAN KEMAMPUAN BERPIKIR KRITIS DENGAN PEMBELAJARAN BERBASIS SCIENTIFIC APPROACH SISWA KELAS $\mathrm{X}$ SMA PANJURA MALANG. JURNAL PENDIDIKAN BIOLOGI INDONESIA, 1, 240-254.

Side, S., Sulastry, T., \& Supardi, R. (2017). Pengaruh Pemberian Kuis di Awal Pembelajaran pada Model Pembelajaran Inkuiri Terhadap Hasil Belajar Siswa Kelas X SMK Negeri 2 Parepare ( Studi pada Materi Pokok Ikatan Kimia ) The Effect of Quiz Giving at Beginning of the Learning Inquiry Model On Learni. Jurnal Chemica, 18(1), 26-34.

Sudrajat, S. \&. (2005). Dasar-Dasar Penelitian Ilmiah. Bandung :Pustaka Setia.

Tatang. (2012). Ilmu Pendidikan. Bandung Pustaka Setia.

Tokan, M. (2019). Correlation between motivation and learning behavior with learning achievement: A case study on the Biology Education Department Faculty of Teacher Training and Education University of Nusa Cendana. In Journal of Physics: Conference Series (Vol. 1157, Issue 4). https://doi.org/10.1088/1742-6596/1157/4/042128

Trisna, I. K., Subagia, I. W., \& Herawati, P. O. (2017). PEMBERIAN KUIS DI AWAL PEMBELAJARAN UNTUK KELAS X MIPA. Jurnal Pendidikan Kimia Indonesia, 1, 60-64.

Turner, I. J., \& Turner, I. J. (2016). Who Wants to be a Biologist? An Excellent Quiz Tool for Students Who Wants to be a Biologist? An Excellent Quiz Tool for Students. Bioscience Education, 7860(March), 10-13. https://doi.org/10.3108/beej.11.c1

Uno, H. B. (2008). Teori Motivasi dan Pengukurannya. Jakarta: Bumi Aksara. 